\title{
The Inhibition of Epileptogenesis During Status Epilepticus by Ginsenosides of Korean Red Ginseng and Ginseng Cell Culture (Dan25)
}

\author{
Chepurnov S.A*\#, Chepurnova N.E., Jin-Kyu Park**, Redkozubova O.M., \\ Pravdukhina A.A., Abbasova K.R., Buzinova E.V., Mirina A.A., \\ Chepurnova D.A., Dubina A.A.*, Pirogov U.A.*, de Curtis M.***, and Uva L.**** \\ Biological Faculty and *Tomography \& Spectroscopy Center of \\ Lomonosov Moscow State University. \\ Moscow, 119992, Vorobievy Gory, Russia \\ **R\&D Center Pharmaco design Co. 305-811 Daejon, Korea; \\ ***Institute Neurology "Carlo Besta", Via Celoria 11, 20135, Milan, Italy
}

(Received July 20, 2007; Accepted September 1, 2007)

\begin{abstract}
Pharmacology of Korean Red ginseng gives us unique possibility to develop new class of antiepileptic drugs today and to improve one's biological activity. The chemical structures of ginsenosides (GS) have some principal differences from well-known antiepileptic new generation drugs. The antiepileptic effect of GS was also demonstrated in all models of epilepsy in rats (young and adult), which have studied, in all models of epilepsy including status epilepticus (SE), induced by lithium - pilocarpine. In our experiments in rats new evidences on protective effects were exerted as a result of premedication by GS. Pre-treatment of several GS could induce decrease of the seizures severity and brain structural damage (by MRI), neuronal degeneration in hippocampus. Wave nature of severity of motor seizures during convulsive SE was observed during lithium-pilocarpine model of SE in rats (the first increase of seizures was 30 min after the beginning of SE and the second - 90 min after. The efficacy of treatment on SE by ginsenoside as expected was observed after no less 3 weeks by daily GS i.p. administration. It is blocked SE or significantly decrease the severity of seizures during SE. The implication of presented data is that combination of ginsenosides from Korean Red ginseng and ginseng cell culture Dan25 that could be applied for prevention of epileptical status development. However, a development of optimal ratio of different ginsenosides $\left(\mathrm{Rb}_{1} \mathrm{Rc}, \mathrm{Rg}, \mathrm{Rf}\right.$,) should consummate in the new antiepileptic drug development.
\end{abstract}

Keywords : ginsenosides: $\mathrm{Rb}_{1}, \mathrm{Rc}, \mathrm{Rb}_{2}, \mathrm{Rd}, \mathrm{Rg}_{1}, \mathrm{Re}, \mathrm{Rf}$, epilepsy, status epilepticus, severity of seizures, MRI, rat brain imaging

\section{INTRODUCTION}

The results of cooperative studies held by Lomonosov Moscow State University (Russia) - KT\&G cooperation suggest that the antiepileptic properties of ginseng and/or various ginsenosides (GS) of Korean Red ginseng, which administrated intranasally in a systematic way, be different with the new generation anti-epileptic drug ${ }^{1-14)}$ in the relief of seizures or several models of seizures or epileptic fits. Simultaneous and positive effects on spatial memory coped with the worsened cognitive function by the seizures that accompanied with experimental amnesia were

\footnotetext{
\# To whom correspondence should be addressed.

(Tel) +007 (495) 939 2792; (Fax) +007 (495) 9394309

(E-mail) chepurnovsa@yahoo.com, chepurnovsa@Gmail.com
}

also demonstrated ${ }^{3,4,8)}$ It has been uncovered that GS could have binding with $\mathrm{GABA}_{\mathrm{A}}$ receptors ${ }^{15-17)}$, thus start creation of the inhibitory and antiepileptic inside system in brain. There was a possibility of applying this medication in this treatment of diseases, which can negatively affects on memory and cognitive function. GS has a protective property on liver ${ }^{18)}$ when is used as combination form with antiepileptic drugs, and it is also effective in the period of reconvulsive after neurosurgical treatment of epilepsy or a neuronal oncology. ${ }^{19)}$ It has been correlated with neuroprotective activity of $\mathrm{Rb}_{1}$ after hypoxic injury in young rats, calcium independent CamKII activity may be involved by GS in the recovery of neuronal cells after hypoxic damage in seizures ${ }^{20,21}$.

Epilepsy is the result of highly complex structural, bio- 
chemical, electrophysiological changes these occur at various level not only within the brain but also in the entire body. We have experience of gensinosodes application for purpose to inhibit the seizures with a difference in the etiology, which were presented at The 8th International Symposium on Ginseng in Seoul in $2002^{11)}$ and at The $1^{\text {st }}$ Beijing Epilepsy Forum in 2004.

New study on ginsenosides in decreasing brain excitability were applied using the model of status epilepticus $(\mathrm{SE})^{22)}$. Status epilepticus is the most dangerous increasing of pathological activity of brain leading to loss of the consciousness and failure of all regulations of vital functions on the border of survival. The International Classification of Epileptic Seizures defines SE as a seizures lasting for more than $30 \mathrm{~min}$ or intermittent seizures lasting more $30 \mathrm{~min}$ from which the patients does not regain consciousness. Any type of seizures may become prolonged, it may develop into SE. W.A.Hauser reported in 1990, that SE occur in $50000-60000$ individuals in the US every year ${ }^{23)}$. D. Lowenstain and B. Alldrege reported in 1998 for Europe - 150000 individuals every year (unfortunately 55000 from them died) ${ }^{24}$ ). The understanding of the mechanisms and complication of SE at the molecular level, which should eventually lead to improve therapy, and treatment strategies today have a greate sense of urgence because of the realization that neuronal apoptosis and necrosis can be triggered very quickly ${ }^{25)}$.

In animals SE can be produced by the administration of pilocarpine. In this model, the preadministration of lithium substantially reduced the dosage of pilocarpine to induce seizures ${ }^{26,27)}$. Lithium is known to synergies the action of cholinomimetics in the CNS such that pilocarpine, but lithium does not synergies the action of cholinomimetics in the periphery (blood pressure and ileum contraction measured) as that seen in the $\mathrm{CNS}^{28)}$.
Following the termination of SE many subjects show, after a delay of several weeks, developed spontaneous recurrent seizures that resemble human temporal lobe epilepsy. After investigation by W.A. Turski ${ }^{26)}$ and E.A. Cavalherio $^{27,29)}$ this model of SE is reminiscent of that human temporal lobe epilepsies which often begins with prolonged SE in infancy and develops with recurrent seizures in later life. lithium-pilcarpine model is one of model of partial limbic seizures that progress to secondary generalized SE. The epileptogenic effect of cholinergic agents depends on the facilitation of burst discharges in hippocampal pyramidal neurons by means a block of the $\mathrm{K}^{+}$transmembrane current. Super-activation of neurons of hippocampus during pilocarpine-induced SE leads to cell death. Seizures-related excitoxicity involves glutamate receptors and $\mathrm{Ca}^{2+}$ influx ${ }^{30}$ ). The EEG is helpful in further dividing SE into those that are generalized from onset, or have a partial onset. The investigation of thresholds and time of SE duration in Li-pilocarpine model is connected not only with blockade of muscarinic $\left(\mathrm{M}_{1}-\mathrm{M}_{5}\right)$ cholinergic receptors, as noted Berkely et $a l^{31)}$ but also with the basic problem of $\mathrm{GABA}_{\mathrm{A}}$ receptors desensitization ${ }^{32)}$.

The main aim of study was researching the possibility of treatment by GS during or before SE.

\section{MATERIALS AND METHODS}

Control registration of basic EEG was done during interictal periods for evaluation of chronicle epileptogenesis. Motor seizures were evaluated with presently accepted scale of motor convulsions in rats. It was evaluate the sets of correlation between neocortex EEG patterns of brain and behavioral manifestation of fits (video record).

Table 1. The scores of behavior and motor seizures during lithium - pilocarpine status epilepticus

\begin{tabular}{cl}
\hline \hline 5 & Very severe tonic-clonic seizures with falling \\
4,5 & Tonic-clonic seizures \\
4 & "Kangaroo pose" tonic seizures body muscle \\
3,5 & Fast jerk (several s. duration), bucking on the hind limb \\
2,5 & Minimal seizures, clonus head muscles \\
3 & Clonus head and limb muscles, jerk of body, jmping \\
2 & Atipical minimal seizures, body jerk \\
1 & Single mioclonic spasm, years jerk, head sake \\
0,5 & Grooming, hiding behavior (abnormal behavior) \\
0 & Normal behavior, no change
\end{tabular}

The table changed from: Kubova, H., Bhuslav, T., Mares, P.: Anticonvulsant effects of clonazepam on chemically induced convulsions. Physiologia Bohemoslovaca, 39, 459-469 (1990). 


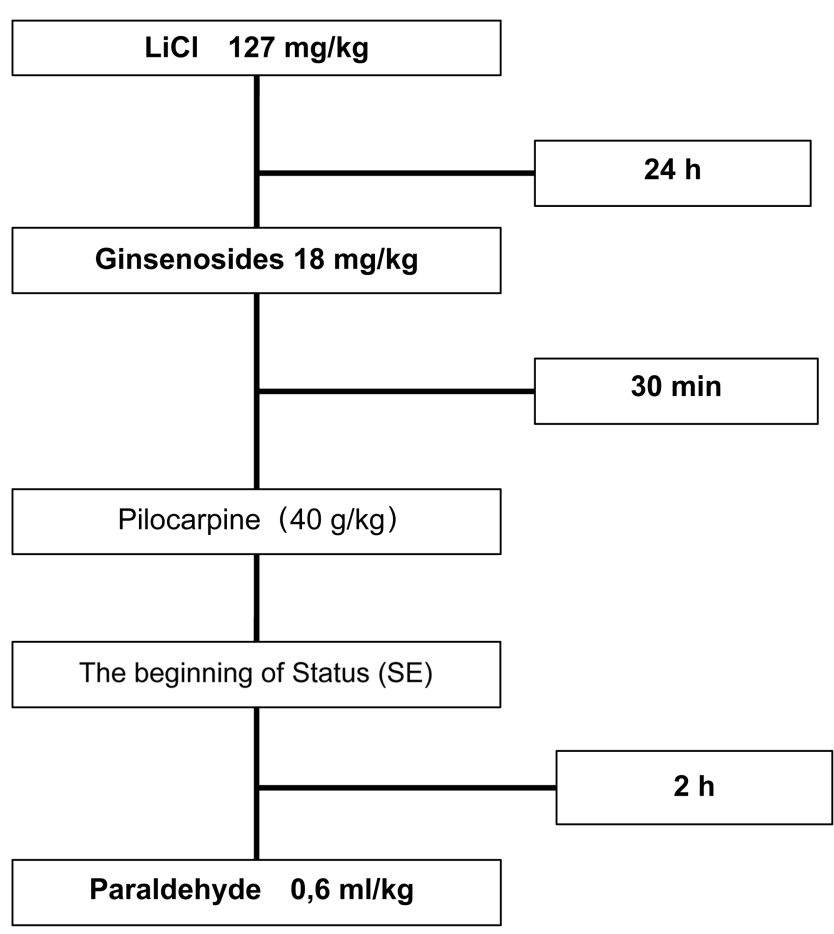

Fig. 1. Protocol of induction of Li- pilocarpine status epilepticus in rats.

\section{The characteristic of lithium-pilicarpine-induced SE}

The subjects were 3-4 months old $(n=41)$ and 6-8 months old $(n=30)$ Wistar rats. In accordance with the protocol (Fig. 1) lithium chloride was prepared as a stock solution in saline $(3 \mathrm{mEq} / \mathrm{kg}-127 \mathrm{mg} / \mathrm{kg}$ body weight) $24 \mathrm{~h}$ before injection of pilocarpine. In this protocol the concentration $\mathrm{LiCl}$ in the blood should be $10 \mathrm{~h}$ after injection $-0.69 \pm 0.03 \mathrm{mEq} / \mathrm{l}, 24 \mathrm{~h}$ after injection - $-0.16 \pm 0.01$ $\mathrm{mEq} / \mathrm{l}^{33)}$. Pilocarpine hydrochloride, was administered at in $2 \mathrm{mi}$ of saline. Following injection of pilocarpine, the rats were observed continuously for behavioral severity of seizures using modified five-stage classification, of severity of seizures (Table 1).

The behavior motor fits were observed in special boxes $(25 \times 30 \times 25 \mathrm{~cm})$. Latency of motor fits and severity of the seizures were measured. Animals were observed for up to 2-3h, followed by paraldehyde («Acrus») administration in concentration $0,6 \mathrm{ml} / \mathrm{kg}(0,1 \mathrm{ml}$ paraldehyde and $0,9 \mathrm{ml}$ of distillated water) to stop SE. The survival of animals after SE was the main problem of developing of chronicle epilepsy. Immediately blocking of SE by diazepam is required after clonic-tonic stage. These animals could be saved during long time after several SE and used them for the further analysis of brain damage by MRI imaging. Mortality was determined $24 \mathrm{~h}$ after experiments/
Magnetic resonance imaging was performed under the Nembutal narcosis on BRUCKER Biospec 70/30 (Germany) Bore MRI system. Ten coronal or frontal images with a slice thickness of $1.5-2.0 \mathrm{~mm}$ were acquired with a multislice gradient echo sequence: $40 \mathrm{~mm}$ field of view (FOV). High resolution gradient echo images were acquired with an echo time (TE) of $6,9 \mathrm{~ms}$, a repetition time (TR) of $500 \mathrm{~ms}$ an acquisition matrix $200 \times 400^{34)}$.

GS were received from KT\&G (Daejon, Korea). The callus cell culture Dan25 from ginseng root was used ${ }^{35}$. The ethanol and buthanol extracts and lyophilic substances of ginsenosides were conducted in Joint-stock association ["Biokhimmash", Moscow ] The content of extracts was evaluated $\left(\mathrm{Rb}_{1}, \mathrm{Rc}, \mathrm{Rb}_{2}, \mathrm{Rd}, \mathrm{Rg}_{1}+\mathrm{Re}, \mathrm{Rf}\right.$,) ginsenosides - 7,552 $\mathrm{mg} / \mathrm{g}$ - biomass of the extract. GS were dissolved in physiological solution $(24 \mathrm{mg} / \mathrm{ml})$, filtrated and injected intraperitoneal in concentration $18 \mathrm{mg} /$ $\mathrm{kg}$. The GS injected at same time.

Stereotaxic method was used for microelectrodes insertion into the cortex and hippocampus under the deep Nembutal narcosis $(47 \mathrm{mg} / \mathrm{kg})$ and local analgesic (Novocain 1\%, «CEVA»). Rats received $5 \mathrm{ml}$ glucose and $0.3 \mathrm{ml}$ Gammavit after operation. EEG record was performed 7 days late.

All experimental protocols used were in complicate with standard and were approved by the European and Moscow University Animal Care and Use Committee.

The latency to seizures onset, duration of status, seizures score were averaged across animals in the same treated group. Comparison between groups were done with an analysis of variance (ANOVA/MANOVA), Criterion "U" (Mann-Uitny) to takes account of BIOSTATISTICA. A statistical difference was determined by a value of $p<0.05$.

\section{RESULTS}

The characteristics of lithium- pilocarpine-induced SE Experimental status epilepticus was induced in adult rats. Before the SE the reactivity on the pilocarpine also registered. It was connected with muscarinic receptors activation. After injection of pilocarpine strong sialozemia, mastication was observed 5-7 min later. Abnormal moving into the box recorded was correlates with hackling reflex (by back pad) down to skin damage and blooding. The salivation, defecation, urination (infrequent ejaculation) were observed 7-15 min after pilocarpine injection. Sudden quick running and head jerk were not compulsory seizures precursor. This model was also char- 
acterized bilateral hind limb struggling, grooming. It was highly repetitive grooming motion with its hind limb without making contact with its body. The first $15 \mathrm{~min}$ following pilocarpine administration the animal can exhibited a brief pause in motor activity. In our experiments the aggressiveness of rats after SE was increased If the SE did not develop the rats be restored after $3 \mathrm{~h}$.

Normally spike and spike-wave discharges in cortex EEG were not observed prior to pilocarpine injections it was correlated with motor seizures only. Wave pattern progressively increasing in amplitude and EEG correlated of seizures stage (Fig. 2). SE was stoped by paraldehyde.

The relative latent period was estimated as the time

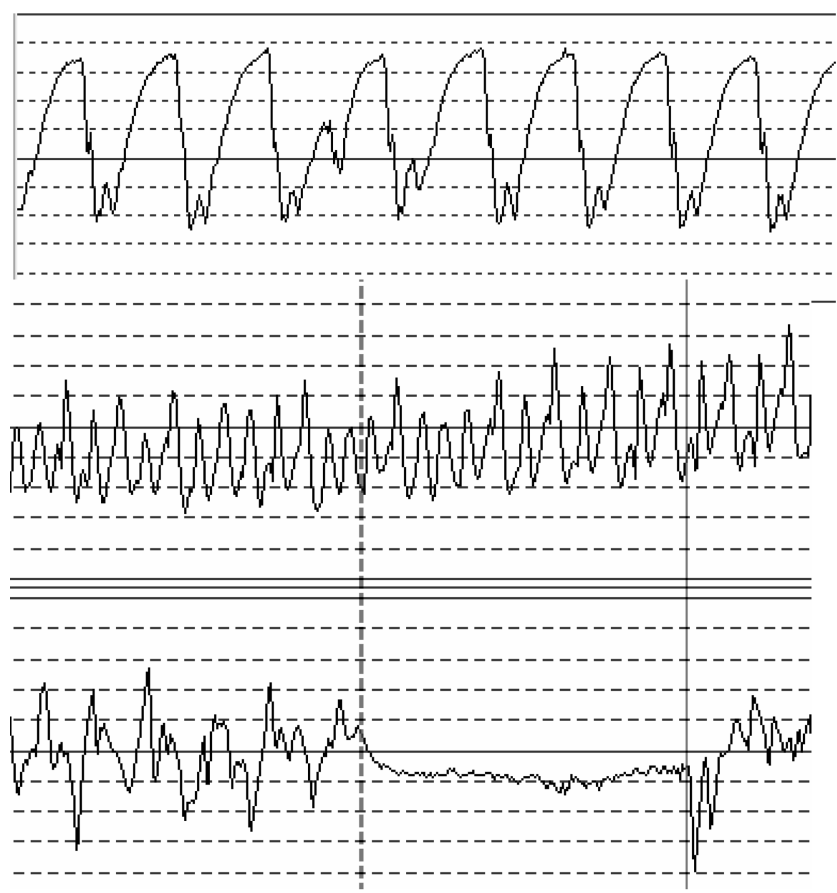

Fig. 2. EEG activity during status epilepticus in rat. 1- EEG recorded in frontal cortex, 2,3 -the first predictor of SE inhibition was the increasing the interval between spikewave discharges. between the injection date and the first observed motor seizure (direct or in any experiments - video monitoring). Latency of SE in rats developing in average was $35 \mathrm{~min}$ (have ranged 5-90 $\mathrm{min}$ ). As usually it begins from 4th score of seizures (extensor reflexes), The duration of which was from several seconds to minutes. The developing of SE include mouth and facial automatisms, head nodding, forelimb clonus, rearing, and rearing with falling. After the jumping the seizures pass on $4^{\text {th }}$ score of fits. Our data in the agreement with results of study SE in rats $^{32,36,37)}$. and in Guinea pigs ${ }^{38)}$.

For any animals smooth developing of SE from $1^{\text {st }}$ to $4^{\text {th }}$ score of seizures was observed. Seizures of $4^{\text {th }}$ score could be recurred.

Wave nature of severity of motor seizures during convulsive SE was observed during lithium-pilocarpine model of SE in rats (the first increasing of seizures was 30 min after the beginning of SE and the second - $90 \mathrm{~min}$ after. Fig. 3.

Some rats demonstrated during SE the limbic epistatus, which characterized by jog reaction - "wet dog shake".

The effects of GS on SE were studied on two experimental protocols: with bolus administration of GS $(n=36)$ : (series 1-3) and with chronically (everyday) administration of GS $(n=25)$ (series 4-6).

\section{EXPERIMENTAL PROTOCOL 1.}

\section{The effects of bolus GS injection}

Series $1(n=12)$ - bolus injection of GS - 30 min before pilocarpine;

Series 2 ( $\mathrm{n}=9)$ - - bolus injection of GS - 30 min after pilocarpine SE has begun;

Series $3(n=15)$ - control saline administration.

The latent period of SE was in control series 38.3+6.9 $\mathrm{min}$ in the case of GS injection before pilocarpine $28.9+2.2 \mathrm{~min}$, but if the GS injected after the SE begins -

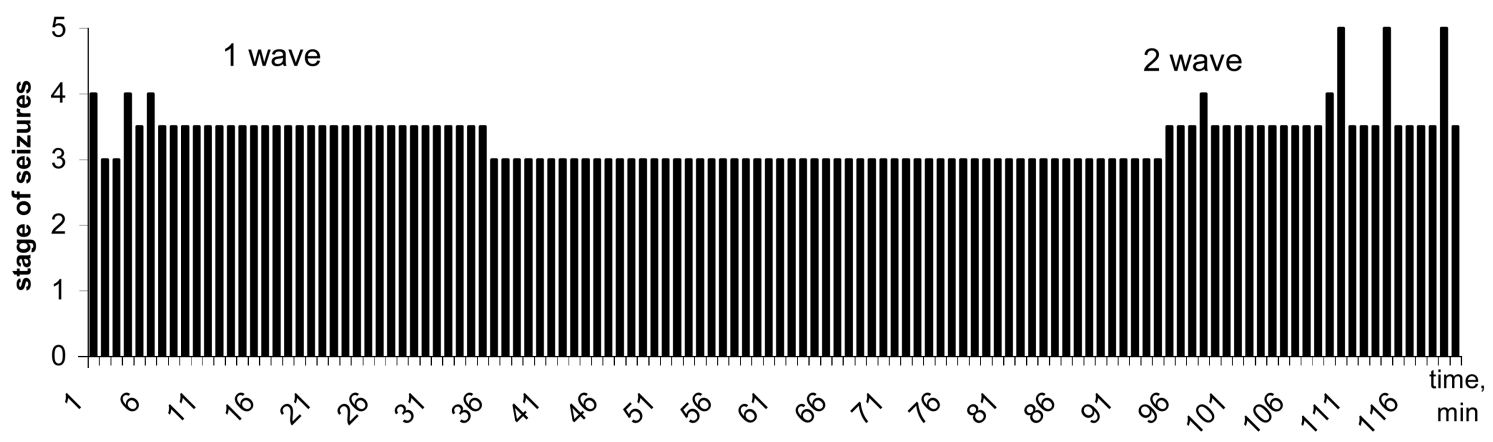

Fig. 3. The two-wave character of pilocarpine SE in rat (single animal from control group). 


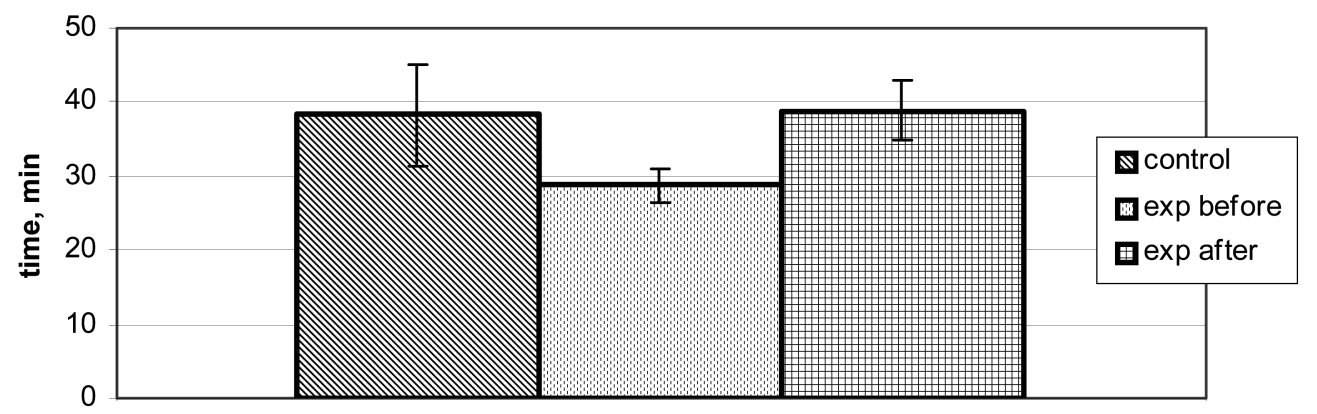

A



B

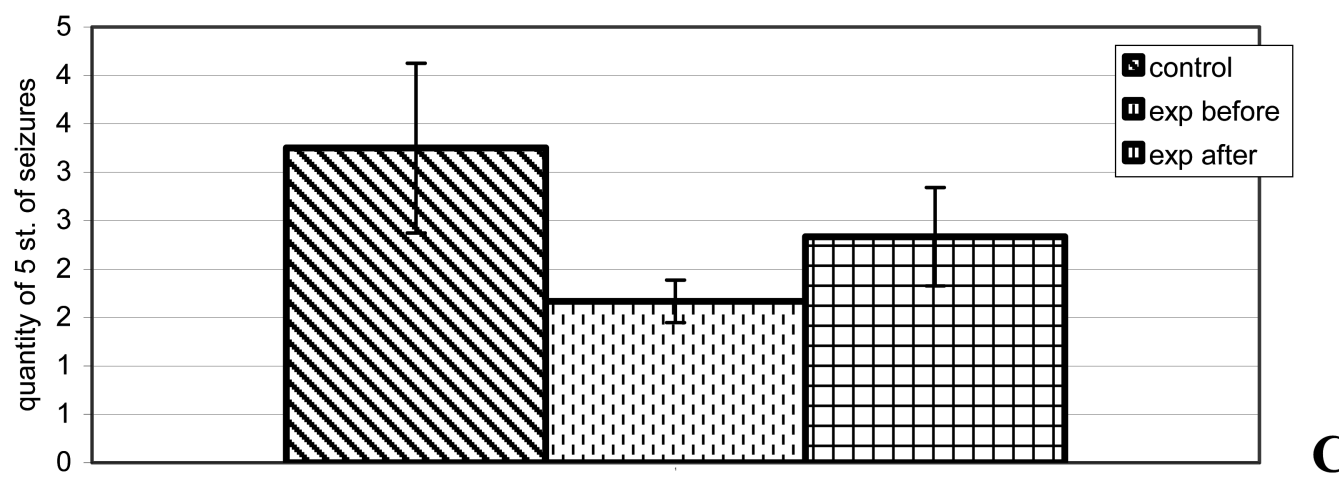

Fig. 4. The comparison of seizures during $2 \mathrm{~h}$ of SE in the rats The first column - control, pilcarpine injection only; the second - average for group of rats received GS 30 min before pilocarpine; the third column - GS injected 30 min after SE begins.

A. The latency of lithium-pilocarpine status epilepticus

B. The number of seizures of $4^{\text {th }}$ and $5^{\text {th }}$ score

C. The number of $5^{\text {th }}$ score of seizures

$38.8+4.1 \mathrm{~min}$. The number and duration of seizures 4 and 5 score were also measured (together $4+5$ score) and separately only $5^{\text {th }}$ score. Fig. 4 . The difference between group of rats in all series were not significance. More demonstrative was the number of $5^{\text {th }}$ score of seizures: in control series 3,3+0,9, in experiments with GS infection before pilocarpine $1,7+0,2$, but for group with GS injection after the beginning of $\mathrm{SE}-2.3+0.5$ (Fig. 4-C). In these experiments the decreasing of "wds" was observed (Fig. 5).

These results permit to make resume that bolus GS administration during SE absolutely non effective, but pretreatment by GS just before pilocarpine injections could inhibit the SE developing. Probably the amount of GS should be increase in bolus injection.

It turned out, that the number of rats, which demonstrated SE is the considerable and manifesting index. If before pilocarpine was injected saline only the $75 \%$ of rats developing SE. In group of rats with GS injection 30 min before pilocarpine SE developed in the $58 \%$ of cases,

We could suppose that in the inhibition of SE could participate several mechanism of GS action. It could be prolongation of IPSP in the hippocampal cells, inhibition of recapture of transmitters and NMDA increasing of intrac- 


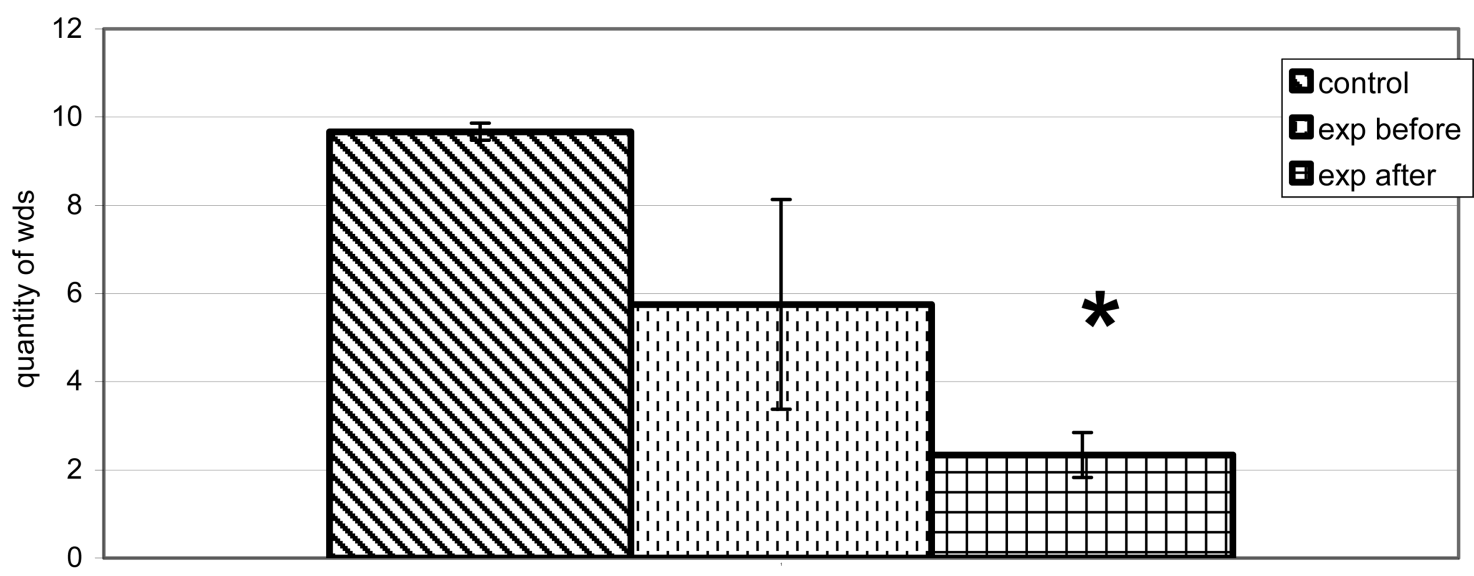

Fig. 5. The average number of "wet dog sake" of rats during $2 \mathrm{~h}$ observation after pilocarpine injections in control ( the first column), after pretreatment by GS (the second column) and GS injection after these begins (the third column)/ * $-\mathrm{p}<0.01$.
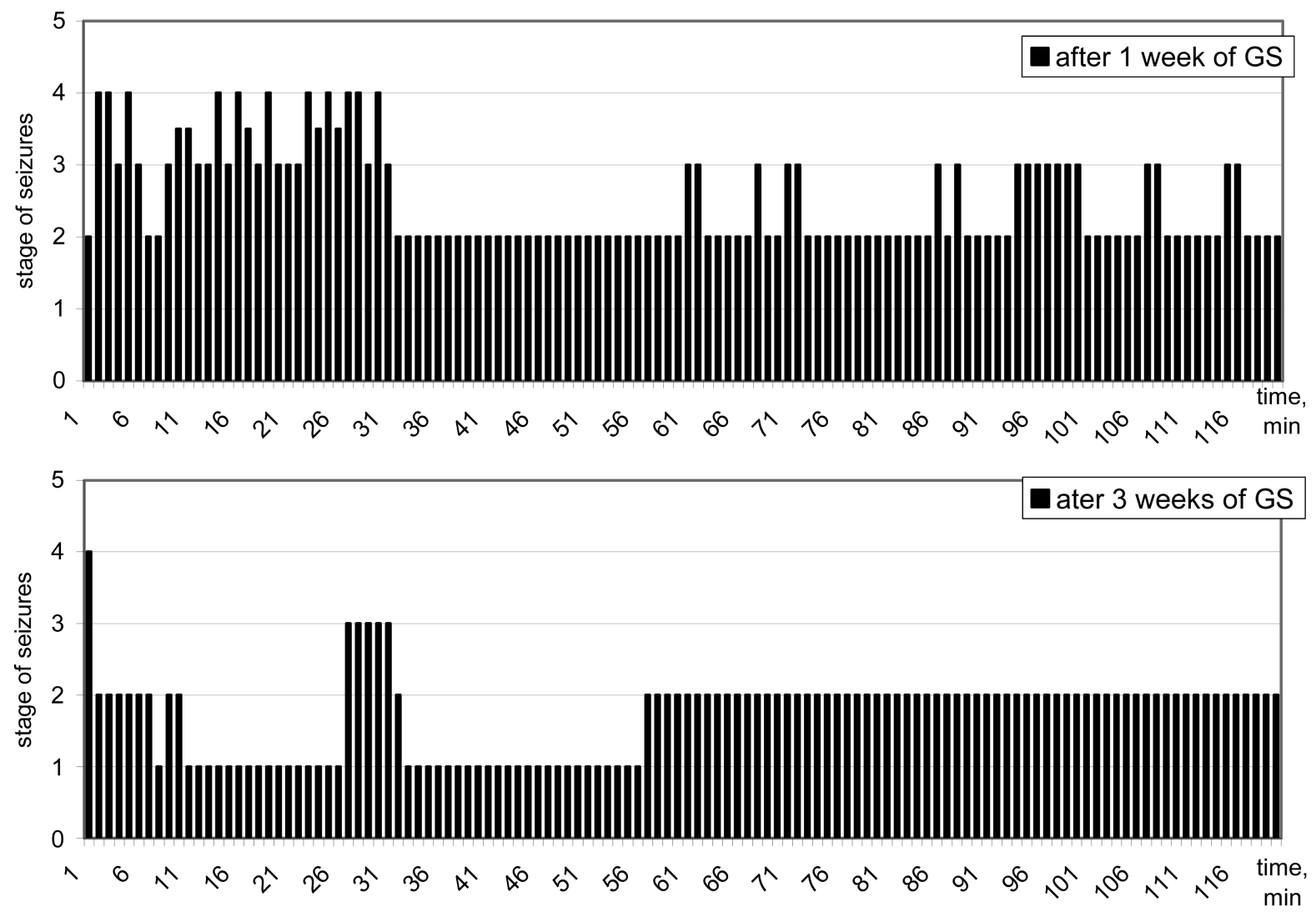

Fig. 6. Dinamic of epipeptogenesis during Li-pilocarpine status epilepticus in rat after one (above) and three weeks (below) of GS treatment.

ellular calcium, All these mechanism decrease seizure excitability of brain and providing the antiepileptical brain system of self defense. It means that the time of GS action and supporting into the blood and brain of GS concentration will be more effective.

\section{EXPERIMENTAL PROTOCOL 2.}

The chronically GS injection.

In a different way performed the chronic administration of GS. In Series $4(n=5)$ : GS administered i.p. for 6 days (on the $5^{\text {th }}$ day, injected together with $\mathrm{LiCl}$ and then on $6^{\text {th }}$ 

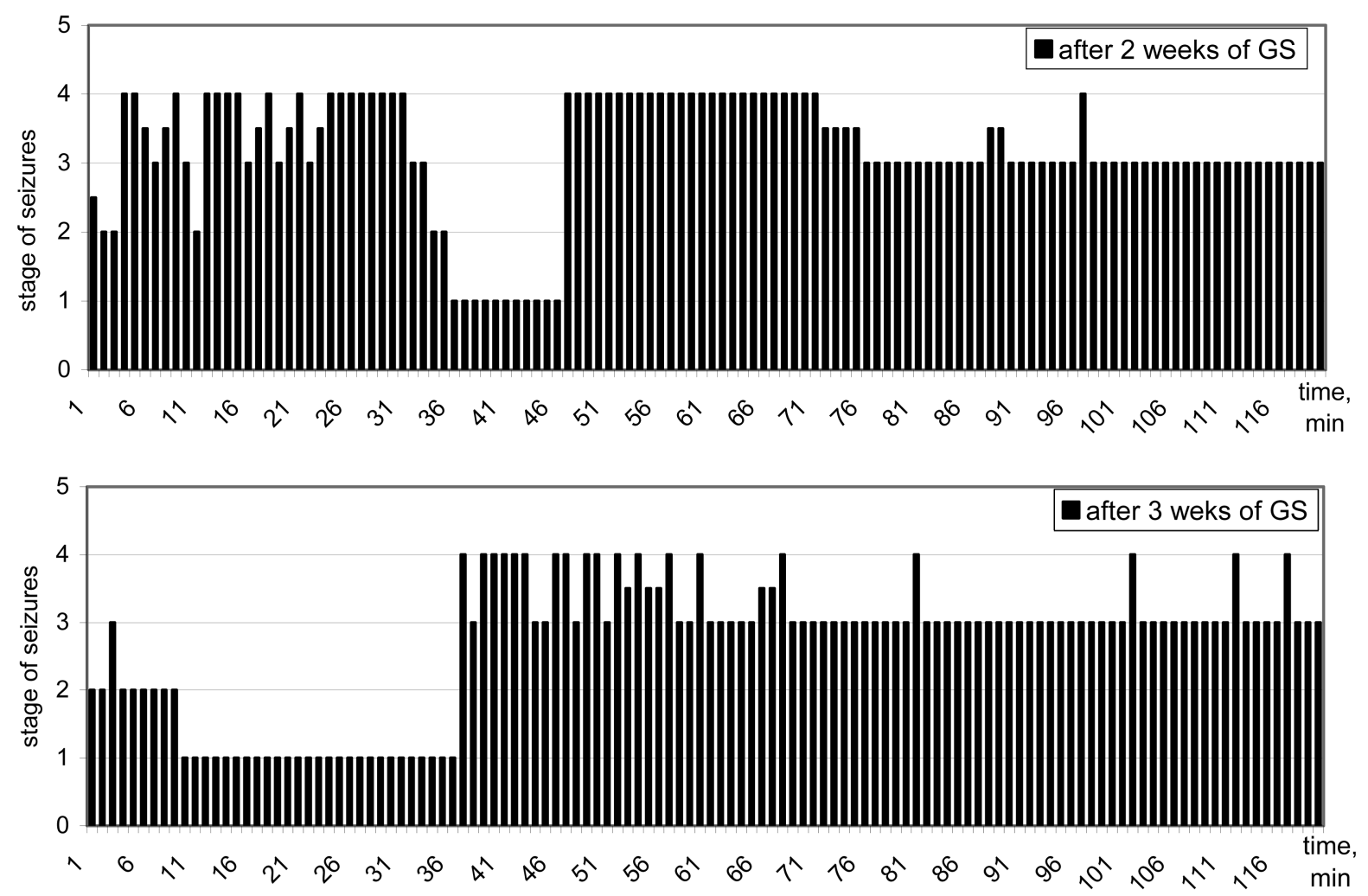

Fig. 7. Dinamic of epileptogenesis during Li-pilocarpine status epilepticus in rat after two (above) and three weeks (below) of GS treatment.

day injected $1 \mathrm{~h}$ before pilcarpine) The experiment repeated three time and consumptive GS use was 3 weeks.

New group rats was tested on the pilocarpine-induced SE development. After that the rats was divided into two equal subgroup series 5 and series 6 . In Series $5(n=5)$ : rats were received daily GS for 4 weeks (extract $18 \mathrm{mg}$ / $\mathrm{kg}$ ), and then experienced 3 lithium-pilocarpine test. It should be written as "test", because SE was not developed in the majority of rats in GS-group. Series 6 was control rats, that received saline only and tested 3 times of lithium-pilocarpine.

It was suggested that daily GS injections as pretreatment will be more effective in the SE inhibition. These experiments were uncovered by the individual differences. As presented at Fig. 6 and Fig. 7, actually the severity of motor seizures during SE was actually decreased. The high $5^{\text {th }}$ score of seizures not observed in all male adult rats.

As presented in the Fig. 7 one week GS treatment induced SE without 5 score of seizures, but two wave of motor fits presented But 3 weeks of GS treatment induced inhibition of SE, but the status epilepticus development was accompanied significantly decreasing the first wave of fits (Fig. 8).

Single-factor analysis of variance shows a significant decreasing the severity of seizures during SE, if it developing after 3 weeks GS treatment.

The inhibition of epileptogenesis connected with muscarinic receptors binding (central effect of pilocarpine) was demonstrated after chronic GS administration (Fig. 9).

The effect of GS could be evaluated as relieved on the seizures development and the duration. The first wave of seizures 4-5 score was completely excluded, but the second wave was never excluded more $3^{\text {rd }}$ score of seizures. The decreasing severity from 4-5 score to $3^{\text {rd }}$ score demonstrated significant inhibition of epileptogenesis.

Motor seizures during expand in the time. This process of SE developing could be evaluated by measuring of stage of severity of motor seizures. The comparison of frequency of occurrence different stage in control group (saline injection) of rats and experimental group rats, treated GS shows that only in experimental group the significant increase number of seizures 1-2,5 score, and the number of seizures 3-3,5 score decreased. (Fig. 10). GS decrease severity of response of brain on the pilocarpine action. 

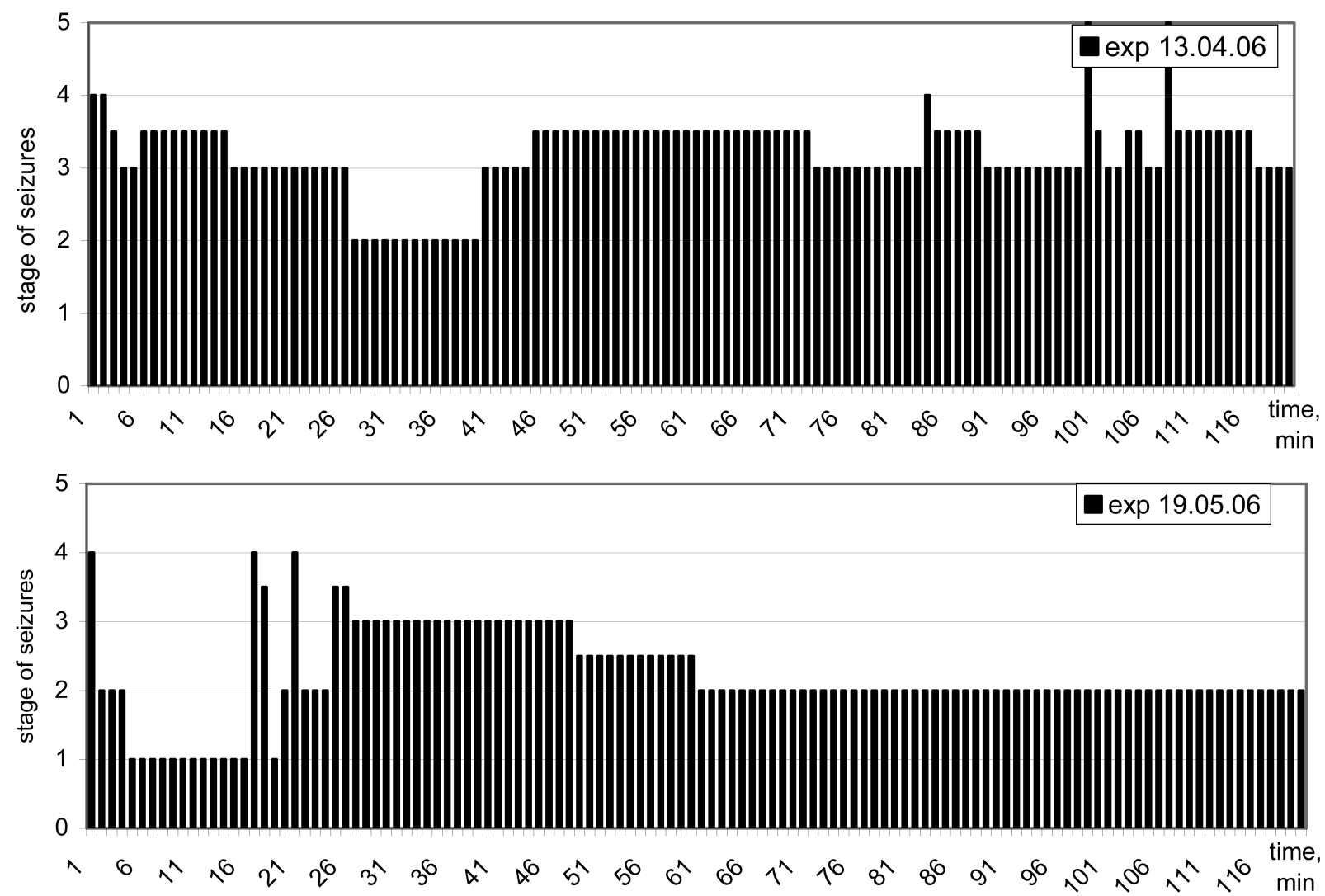

Fig. 8. Longtime effect of GS treatment during 4 weeks, SE pilocarpine test was repeated after 4 weeks of treatment of GS.

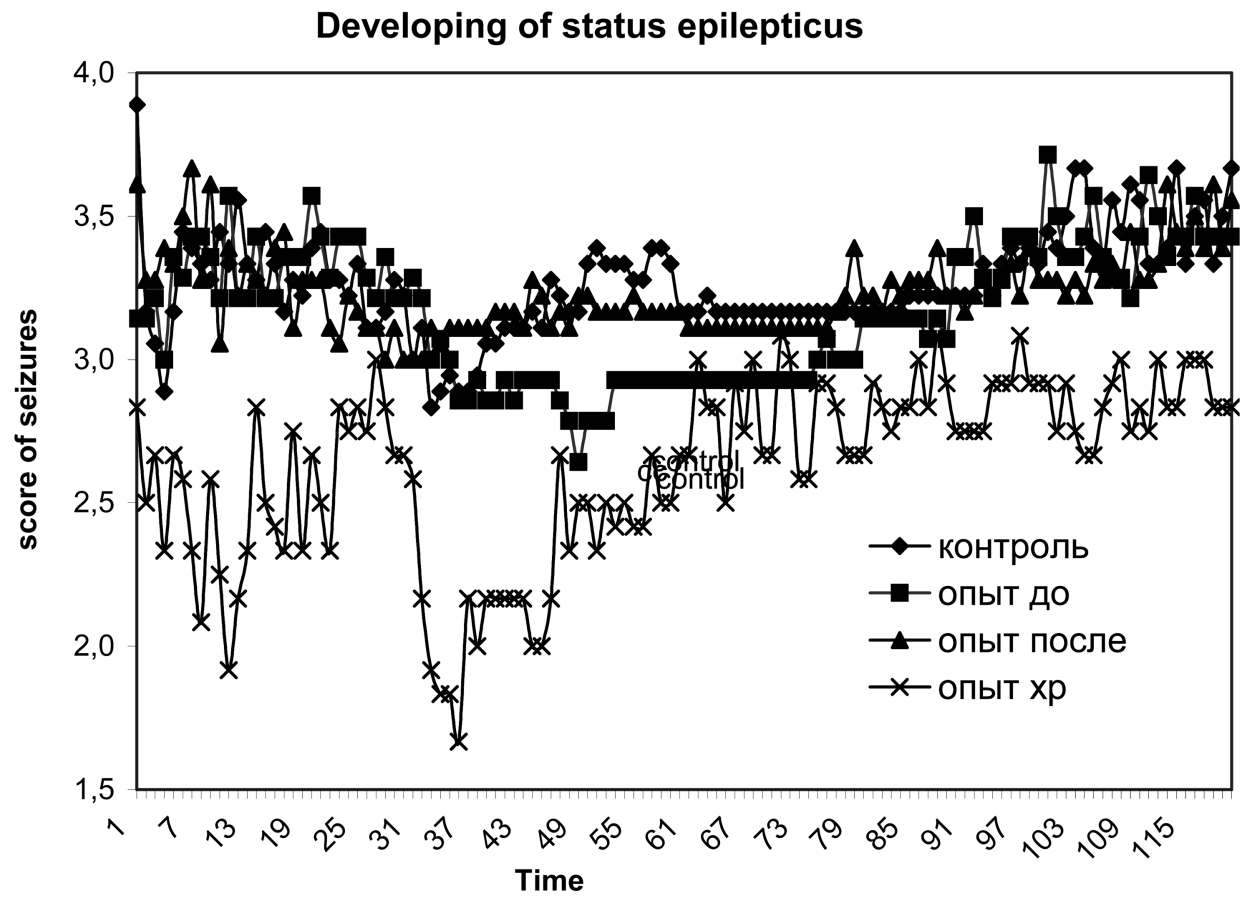

Fig. 9. Summarized average data of SE developing, Significant decreasing the severity of SE in experiments with chronic GS injections. Key top-down: 1-control, 2-injection of GS before pilocarpine, 3-injection of GS after the SE beginning, 4-chronic injection of GS 3 weeks. 
A

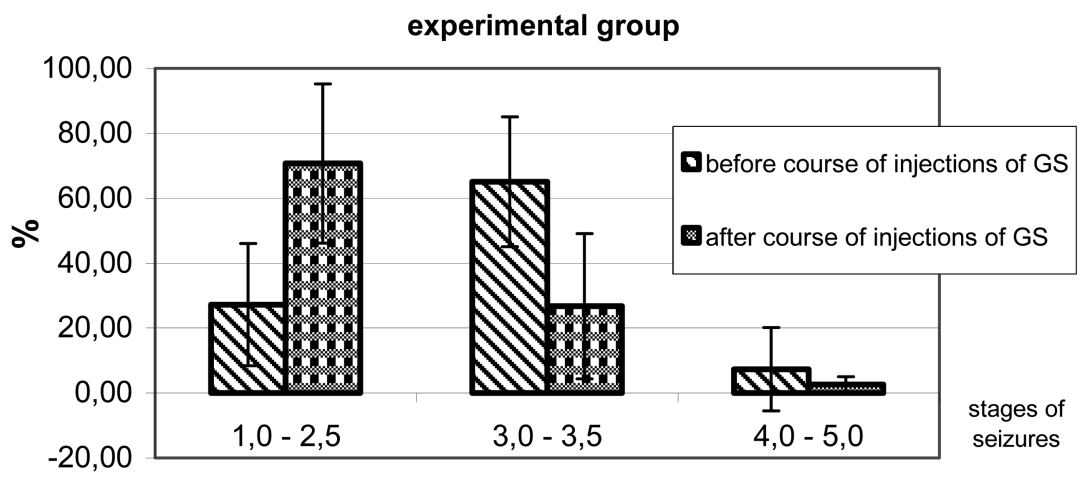

B

control group

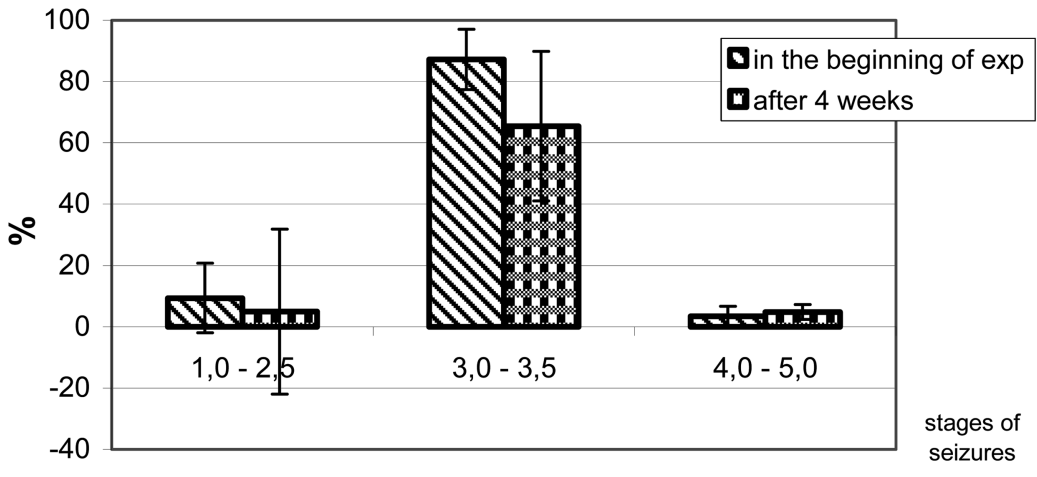

Fig. 10. Average frequency of different scores of SE in rats, treated 4 weeks of GS (A) and control group (B).

The effects of ginsenosieds on the epileptogenes in rats in Li-pilocarpine test



$\%$ of animals with status

Fig. 11. The number of rats which demonstrated LI-pilocarpineinduced status epilepticus 1-control, saline injections, 2bolus GS injection $30 \mathrm{~min}$ before pilocarpine; 3chronicle GS injection during 3 weeks before pilocarpine.

The closing series of experiment was performed on Wistar rats, 6-8 months old ( $n=15$ saline; $n=15$ GS injection). The SE before GS treatment was compared with after 4 weeks of GS injections. The result demonstrated on Figs. 9 The severity of seizures in control rats did not change. The mortality was high in control group. Singlefactor analysis of variance shows the significant differ- ence between SE test before GS and after GS treatment only, but not for control group with saline injections. It was note before that SE developed in control group $(n-=24)$ in $75 \%$ of case, but in experiments with chronical GS injection SE $(n=14)$ developed in $43 \%$ of cases (Fig. 11).

It is possible to suggest that chronic daily treatment of GS induce significant inhibition or significant decrease in the severity of SE.

However, it should be correctly noted that the most of rats treated by GS were completely not "flow into" SE.

MRI imaging rat brain and diagnostic of long-term alterations of brain tissue following status epilepticus.

A number of electrophysiological and neuroimaging procedures are used for the presurgical localization of the epileptogenic focus. Together with clinical data, noninvasive imaging procedure such as MRI, PET, SPECT etc., are used to provide information on the focus that can be further investigated using invasive EEG recordings ${ }^{39}$. MRI are based on the same physical principle, as indicated by the first two letter of their acronyms: they measure the resonance frequencies (of protons) after stimulation by high-frequency radio pulses in high, steady magnetic fields. Our idea was to determined what is brain 

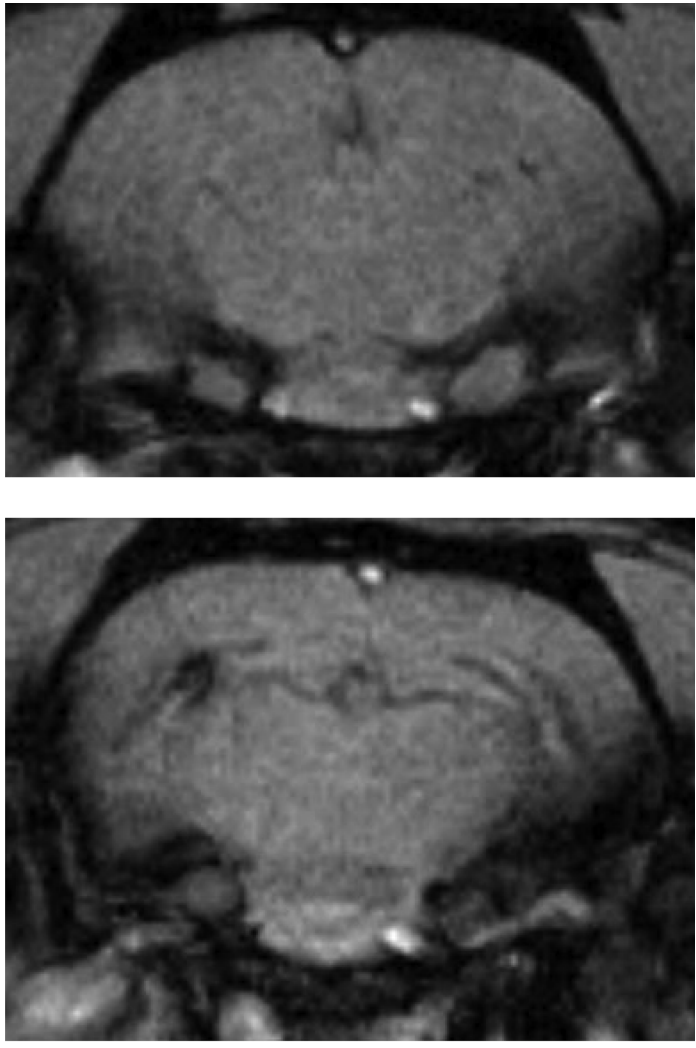

Fig. 12. (a, b) Frontal scan (MRI) of rat brain with left hippocampus damage and piriform lobes. Rat has experience of $3 \mathrm{SE}$ (control, rat: eOg1r1_sc2c17).

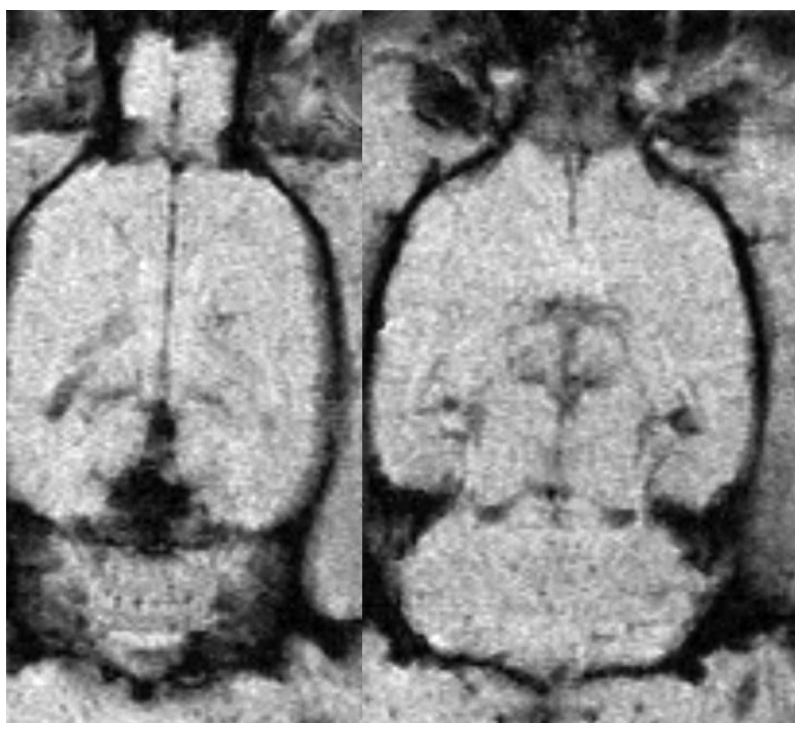

Fig. 13. (c, d) High resolution coronal images (MRI imaging) of the rat brain, experienced four SE (control, rat: eOg1r8s15, eOg1r8s14).

alterations in MRI after several cases of SE. MRI was performed in the agreement of the recommendation of $\mathrm{N}$.

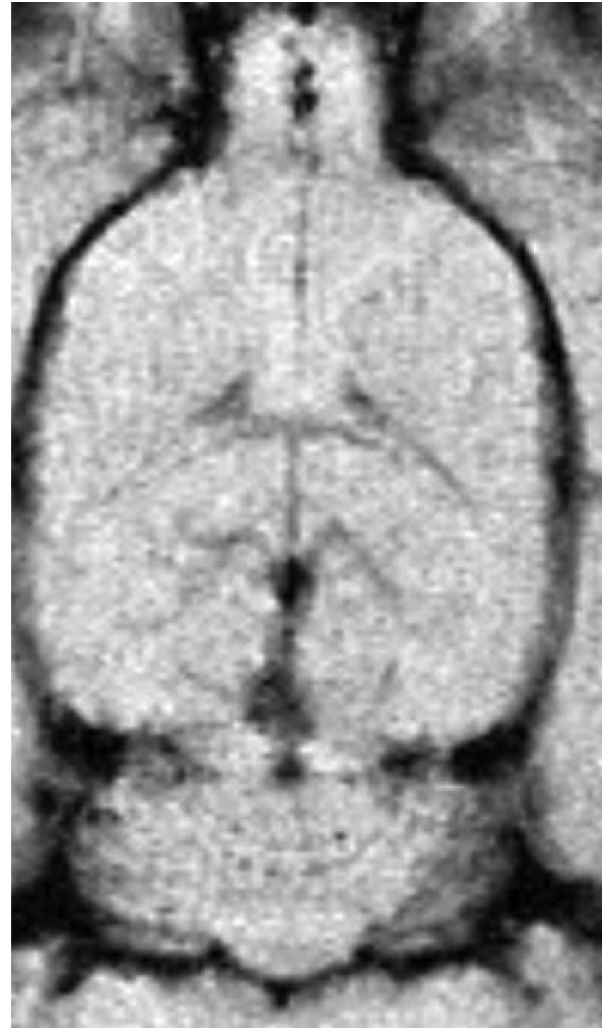

Fig. 14. (e) MRI imaging of the coronal slice of rat brain. Rat expired $3 \mathrm{SE}$ and received GS during 4 week (different echo and MRI regime) (rat eOg2r4_sc15_GS).

van Camp et al., ${ }^{34)}$.

All MRI slices of each animal (5 - control, 5 with GS) were examined, but for final analysis only slices were considered that include relevant brain structures. The imaging of normal rats and treated GS rats was studied. As show on the Figs. 12-16, there is a focal damage in the hippocampal structures, piriform lobe, cortex and different pathology of brain ventriculus. A priory conclusion is that long-term abnormalities in rats one months after several SE could be bring to light by MRI. It is important data that this over patching registered one months after 3 or 4 SE. All rats treated GS (it means the decreasing of severity of SE ) not observed brain abnormality, as compare with control rats.

The temporal evolution of the lesions in the lithiumpilocarpine model of epilepsy in the rat with MRI to determine the progressive morphological change occurring before he appearance of chronic epilepsy was studied by Catherie Roch and co-authors ${ }^{40)}$. The authors studied MRI $2 \mathrm{~h}, 6 \mathrm{~h}$ and $24 \mathrm{~h}$ after SE. it was demonstrated also that in the hippocampus, the correlations between histopa- 




Fig. 15. (f) (sequential) MRI imaging the same slice of rat brain. Rat received GS 4 weeks and 3 SE. (rat eOg2r4_ sc5s15ec1_GS).

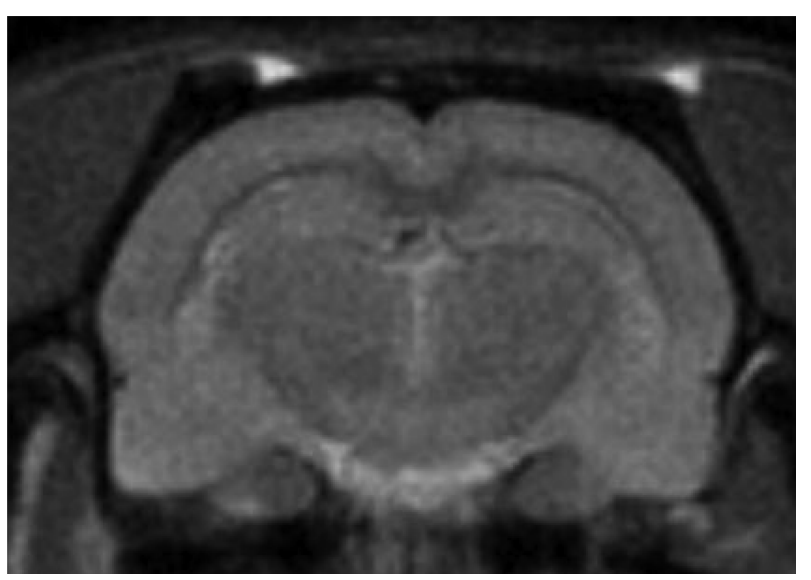

Fig. 16. (g, h) The frontal slices, coronal scan of rat brain. Rat expired $3 \mathrm{SE}$ and received GS during 4 week (different echo and MRI regime) (slices: eOg2r4s17ec1_GS and eOg2r4s17ec2_GS).

thology and $\mathrm{T}_{2}$-weighted signal underscored the progressive constitution of atrophy and sclerosis, starting 2 days after SE. The results of repeated SE did not investigate.

Our data permit to make the conclusions about wave nature of severity of motor seizures in rats during motor convulsive SE, induced by lithium-pilocarpine (the first increasing of seizures was $30 \mathrm{~min}$ after the beginning of SE and the second - 90 min after. The efficacy of treatment SE by GS as expected observed after no less 3 weeks (daily GS i.p. administration). It is blocked SE or significantly decrease the severity of seizures during SE. The implication of presented data is that combination of GS from Red Korean ginseng and ginseng cell culture Dan25 could be applicated for prevention of epileptical status development.

\section{DISCUSSION}

Ginseng has inexhaustible potential, as effective remedy to preserve of health of Nations in the World. It is supported the most new effort with Korean Red ginseng using the modern molecular and genetic methods and new neurobiolgical ideas. Saying figuratively "ginseng one kept the secretions of all pharmacological company have taken together in East and West".

There are many targets in our suffering body, where its compound have therapeutic action. This is the problem of biological sciences to cover and to know these targets in the harmony of all absolute rich ginseng substances. So, the question is: what we should recommend for any decease treatment: ginseng? ginseng's extracts? ginsenosides complex? single ginsenoside as high specific biochemistry regulator of specific biological function in organisms. Pharmacological effects attributed to GS have been shown in the central nervous system, the cardiovascular system, the endocrine system, and the immune system. They are thought to have antineoplastic, antistress, and antioxidant properties. Now we stored knowledge how the GS act at the levels of organism, organs, tissues, cell, membrane, channels and genes.

There are no the insuperable contradictions today between using ginseng of official medicine and complementary and alternative medicines (CAMs), including herbal medicines ${ }^{41-43)}$. It has a long history of use across several cultures to treat a variety of ailments, including memory loss, if it connected presumably with cholinergic system of brain. Much really scientific research has been published on the pro-amnestic effects of ginseng in animal studies, but evidence for such effects in humans unfortunately is lacking ${ }^{44)}$. As M.Spinella ${ }^{41)}$ wrote not long ago in $200142 \%$ of Americans surveyed have recently used at least one such form of CAM therapy. A large proportion of CAM consumers (40\%) do not dis- 
close their use of CAMs to their physicians, and it was estimated that 15 million American adults took prescription medications concurrently with herbal medications in 1997. It is very important that $24 \%$ of people with epilepsy in one tertiary care epilepsy clinic reported using CAMs. ${ }^{41)}$

The maximal questions should emerged concerning the central effects of GS. Where are documentary scope using GS in neurology?

The main contradiction arises every time, when the questions of application of ginseng in neurology discussed. On thing is the anti-epileptical efficacy of different combination of ginsenosides, another thing is the note such as : ..."most of the ginseng available in the American market is made from the root of American ginseng suggests, that people with epilepsy, especially those with history of status epilepticus, should not take ginseng" ${ }^{45)}$.

Our presented new data are accordance with the results demonstrated these authors. Enriched $\mathrm{Rb}_{1}$ extracts really have anti-convulsant effect. But we cannot agree with assumption that "some ginsenosides are anticonvulsant, but that other component of the whole extract from roots or leaves/stem are proconvulsant or alternatively contain components that neutralize the anticonvulsant affect of the active components " $[45$, p. 21.] However there are not direct evidence which kind of substances from ginseng extract (e.g., in form of tea powder) have proconvulsant effect. Without doubt the problem of efficacy of purified GS in clinic of epilepsy will be required further testing.

Park J-K. ${ }^{46,47)}$ and Lee J-H. ${ }^{48)}$ convincing demonstrated on the kainite model of SE that GS (e.g. - Rd) have protective effect on the neurotoxic response of brain. Pretreatment with whole ginseng extract has been shown also to reduce the neuronal loss. ${ }^{48,49)}$, but we not need to separate the anticonvulsant effect and neuroprotective effect, because reduction of convulsions leads to minimization of neurons death. We should underline that pretreatment with GS (obligatory include $\mathrm{Rb}_{1}$ ) have curative action in rats manifesting in the abolish or significant decrease in experimentally induced SE lithium-pilocarpine model.

Lian X-Y et al. ${ }^{45)}$ demonstrated using three models of seizures (PTZ induced seizures, pilocarpine-induced SE and kainite-induced SE) that fixed combination of GS has anticonvulsant properties. Applied partial purified extract content $\mathrm{Rb}_{1}(24.8 \%), \mathrm{Rb}_{3}(46,4 \%)$ and $\mathrm{Rd}(13.1 \%)$ It is agree with our earlier publication about ginsenoside $R b_{1}$ has anticonvulsant effect ${ }^{45}$.

Using lithium-pilocarpine model of SE has neurochemistry specificity: 1) its is result of cholinergic muscarinic receptor activation, 2) deep damage of brain could be observed after SE. Exactly that character of lithium-pilocarpine-induced $\mathrm{SE}$ de fide that $\mathrm{SE}$ is fruitful animal model of temporal lobe epilepsy (TLE) in human. Many TLE patients develop pharmacoresistance : seizures can no more be controlled by antiepileptic drug. Animal models of TLE appear particularly helpful to study molecular mechanisms of hyperexcitability and pharmacoresistance 50) and to new generation of antiepileptical drugs, including GS.

New experimental methods of neurobiology give us possibility to understand several mechanisms of GS action. The ginsenosides be drawn into regulation of synaptic transmission have beneficial effects on protecting neuronal or non-neuronal cells from degeneration. For example, GS modulate neurotransmitter release by inhibiting the uptake of GABA, glutamate, and biogenic amines in the presynaptic terminal ${ }^{16)}$. They also act on the postsynaptic dopamine receptors ${ }^{51)}$ and $\mathrm{GABA}_{\mathrm{A}}$ receptor $^{17,52,53)}$, or $\mathrm{Ca}^{2+}$ channels ${ }^{54)}$, and modulate the efficacy of synaptic transmission $^{55)}$. It was reported that in vivo treatment of ginsenoside $R b_{1}$ protected hippocampal CA1 pyramidal neurons from lethal ischemic damage ${ }^{56,57)}$ and improved learning and memory probably by facilitating also cholinergic function ${ }^{58)}$. It is possible to assume that one new mechanism of antiepileptic action of $\mathrm{Rb}_{1}$ (and probably, other ginsenosides) in pilcarpine-induced seizures consist in the modulation of extracellular signal-regulated kinase $1 / 2$ signaling cascade ${ }^{31)}$.

The role of NMDA receptors ascertained in the mechanisms of epilepsy, stroke and other neurodegenerative deceases. NMDA receptor-mediated pilocarpine-induced seizures, that demonstrated Smolders et $a l^{59)}$ in freely moving rats by microdialysis. With regard these data we must draw for explanation GS effects by new results of Kim S. et al., ${ }^{60,61)}$, discovered , that GS could inhibit NMDA receptor-mediated epileptic discharges in cultured hippocampal neurons. This is clarify itself both effects anti-seizures and protective neurons death. Ginsenoside $\operatorname{Rg}_{1}$ was shown to enhance neurogenesis of dentate granule cells, which may contribute to functional recovery of hippocampus from ischemia ${ }^{62)}$. It was further shown that $\mathrm{Rb}_{1}$ can protect spinal cord neurons from glutamate toxicity and induce neurite outgrowth ${ }^{63)}$, which might involve protein synthesis of neurotrophic factors at the gene expression levels ${ }^{64)}$. All these studies strongly indicate that GS may function as a positive modulator for neurons undergoing degeneration after injury. Because problem of SE connected with severe hypoxia, it is impor- 
tant to draw date, recently presented by Park J-K., ${ }^{20)}$. It was shown that that calcium independent CaMKII activity may be involved in the process of ginsenoside $\mathrm{Rb}_{1}$-mediated recovery of neuronal cells after hypoxic damage. The pretreatment with $\mathrm{Rb}_{1}$ prior to hypoxic stimulation reduced animal death to $12 \%$, and also significantly reduced the recovery time from hypoxia-related. $\mathrm{Rb}_{1}$ also significantly reduced levels of lactate dehydrogenase release from primary hippocampal neurons, indicating increased neuronal survival by $\mathrm{Rb}_{1}{ }^{20}$. The normalization of brain neuronal networks during SE by GS promote the direct effects of GS on the base mechanisms of neurons excitability or inhibition. In such a way, GS could modify electrical evoked neural; activity in rat hippocampal slices ${ }^{65)}$. Lee $\mathrm{J}-\mathrm{H}^{66)}$ recently shows that ginsenoside $\mathrm{Rg}_{3}$, could mediated brain $\mathrm{Na}^{+}$current inhibition. The shortterm changes (Kv4.2potassium channels) and the longterm changes (loss of selective type of interneurons, excitatory circuits by mossy fiber sprouting) that promotion the epileptic state and recurrent seizures in limbic structure are connected with cholinergic mechanisms. GS could include in the processes of normalization cholinergic transmission and long-term effects of apoptosis ${ }^{67}$ ) and neuron survival ${ }^{68)}$.

It is follow in the conclusion to remind about complicity of GS in stress reactivity and influence on the pituitary-adrenocortical system. Long-term premedication with GS, especially $\mathrm{Rg}_{1}$ (a functional ligand of glucocorticoid receptor), could involved endocrinological defense mechanisms ${ }^{69,70)}$ during status epilepsy.

\section{AKNOWLEDGEMENT}

This work was supported by- RFBI grants, Russia, 2002-2006 (No 00-04-48809; No 02-04-48449); Cariplo Foundation, Landau Network - Centro Volta, Italy 2004/2005.

\section{REFERENCES}

1. Chepurnov, S. A., Chepurnova, N. E. and Park, Jin-Kyu.: Ginseng could counteract aging, or brain disorders (As preventive medicine). In: "The Korea Times". Seoul. September 11, 3 (1994).

2. Chepurnov, S. A., Chepurnova, N. E., Jin Kyu Park, Lubimov, I. I., Buzinova, E. V. and Kabanova, N. P.: Central effects of saponin components and polysaccarides fraction in Korean red ginseng. Proceedings of the 5th Life of Science Symposium on Biomedical research with Korean Red Ginseng. KGTRI, Korea. 83-108 (1994).
3. Chepurnov, S. A., Chepurnova, N. E., Park Jin Kyu, Lubimov I. I., Buzinova E. V., Kabanova N. P. and Ki Yeul Nam.: The central effects of saponin components and polysaccarides fraction from Korean Red Ginseng. Korean Journal Ginseng Sci. 18, 165-174 (1994).

4. Chepurnov, S. A., Chepurnova, N. E., Park, Jin Kyu, Buzinova, E. V., Sato, M., Borzenkov, V. M. and Lubimov, I. I.: Cognitive functions and epilepsy. - The improving influences of the triol ginseng saponins and neuropeptides. Symposium: "The molecular and the cells genetic mechanisms of adaptive behavior". Saint-Petersburg (1994).

5. Chepurnova, N. E., Chepurnov, S. A., Park, Jin-Kyu and Nam, Ki-youl.: Febrile hyperthermia-induced seizures and perspectives of cognitive functions development (experimental study). Epilepsia. 36. Suppl. 3, S46 (1995).

6. Chepurnov, S. A. and Chepurnova, N. E.: Epilepsy and Ginseng - modern Euro-Asian Art. The Int. Congress "Epilepsy A Developing World". Chine, Beijing. April 22-28 (1996).

7. Park, Jin-Kyu, Chepurnova, N. E., Abbasova, K. R. and Chepurnov, S. A.: The influence of ginsenosides of Korean Red Ginseng on the febrile hyperthermia-induced seizures in the rat: long term inpacts for development of the cognitive functions. In: Inaugural Congress of Asian \& Oceanian Epilepsy Organization. '96 AOEO. September 6-7, 1996. Seoul, Korea 34 (1996).

8. Chepurnov, S. A., Chepurnova, N. E., Park, Jin-Kyu, Abbasova, K. R. and Klueva, U. A.: Effects of seizures activity in neonatal period on the learning and relearning in adult rats. (The improving role of the giunsenosides). In: Inaugural Congress of Asian \& Oceanian Epilepsy Organization. '96 AOEO. September 6-7, 1996. Seoul, Korea. Abstr. O-1-5, 16 (1996).

9. Chepurnov, S. A. and Chepurnova, N. E.: Ginsenisides in epileptogenesis of the developing brain. The $1^{\text {st }}$ Congress of Asian \& Oceanian Epilepsy Organization. // '98 AOEO. October, 1998. Taiwan. Taibei. (1998).

10. Chepurnov, S. A., Park, Jin Kyu, van Luijtelaar, E. L. J. M., Chepurnova, N. E., Strogov, S. E., Mikhaylova, O. M., et al.: Antiepileptical properties of ginsenozides from Korean Red Ginseng and ginseng cell cultures (dan25) In: The Plant Resources Societ.y of Korea. The $7^{\text {th }}$ International Symposium. "Proceding of Internatioonal Symposium for the Development of Medical Plants." Cultural Center for InjeKun. Korea. October 27-29, 2000, á 116-122 (2000).

11. Chepurnov, S. A., Park, Jin-Kyu, Chepurnova, N. E., et al.: Ginseng in the mechanisms of brain excitability regulation The way for progress. Advances in Ginseng Research (Ed. Nam-In Baek). 84-95. (2002).

12. Park, Jin-Kyu, Chepurnova, N. E. and Chepurnov, S. A.: Ginseng in treatment of epilepsy: "Pro" and "contra" of plant medicine. XVII Konferencia Naukowa na temat Padaczki Polskiego towarzystwa epileptologii. Lodz. 8-10 maja, 2003./ 
IEpileptologia. Supl. 1, 11, 92-93 (2003).

13. Chepurnov, S. A., Park, Jin-Kyu and Chepurnova, N. E.: Ginsenosides $\left(\mathrm{Rb}_{1}, \mathrm{Rb}_{2}, \mathrm{Rc}\right)$ in the mechanisms of antiepileptogenesis. XVII Konferencia Naukowa na temat Padaczki Polskiego towarzystwa epileptologii. Lodz. 8-10 maja, 2003. // Epileptologia. Supl. 1. 11, 91-92 (2003).

14. Chepurnova, N. E., Park, Jin Kyu, Buzinova, E. U. and Chepurnov, S. A.: The ginsenosides in the mechanisms of memory and epileptogenesis. Russian. Physiological Journal named I.M.Sechenov. 90, Part 1. 286-187 (2004).

15. Tsang, D., Yeung, H. W., Tso, W. W. and Peck, H.: Ginseng saponins: influence on neurotransmitter uptake in rat brain synaptosomes. Planta Medica, 3, 221-224 (1985).

16. Kimura, P. A., Saunders, H. S. Kim, H. M. Rheu, K. W. Oh and Ho, I. K.: Interactions of ginsenosides with ligand-bindings of $\mathrm{GABA}_{\mathrm{A}}$ and $\mathrm{GABA}_{\mathrm{B}}$ receptors, General Pharmacology: The Vascular System, 25(1), 193-199 (1994).

17. Jeong, T. C., Kim, H. J., Park, J. I., Ha, C. S., Park, J. D., Kim, S. I. and Roh, J. K.: Protective effects of red ginseng saponins against carbon tetrachloride-induced hepatotoxicity in Sprague Dawley rats, Planta Medica, 63(2), 136-140 (1997).

19. Chang, Y. S. and Seo, E. K.: Gyllenhaal, Ch. Panax ginseng: A Role in Cancer Therapy. Integrative Cancer Therapies, 2 , 13-33 (2003).

20. Park, Jin Kyu, Namegung, Uk, Lee, Chang Long, Park, Jong Oh. Jin, Sung-Ha, Kwon, Oh Bin et al.: Calcium-independent CaMKII activity is involved in ginsenoside $\mathrm{Rb}_{1}$-mediated neuronal recovery after hypoxic damage. Life Science 76, 1013-1025 (2005).

21. Shen, L. and Zhang, J.: Ginsenoside $\operatorname{Rg}_{1}$ increases ischemiainduced cell proliferation and survival in the dentate gyrus of adult gerbils. Neuroscience Letters 344, 1-4 (2003).

22. Chepurnov, S. A., Chepurnova, N.E. and Redkozuova, O.M.: Status epilepticus - a new mrchnisms and way of inhibition (lithium-pilocarpine model). Uspekhi Physiologicheskih Nauk (in Russian), 36, 68-83 (2005).

23. Houser, C. R. and Esclapez, M.: Down regulation of the alpha5 subunit of the $\operatorname{GABA}(\mathrm{A})$ receptor in the pilocarpine model of temporal lobe epilepsy. Hippocampus. 13, 633-645 (2003).

24. Lowenstein, D. H. and Alldredge, B. K.: Status epilepticus. N. Engl. J. Med., 338, 970-976 (1998).

25. Status epilepticus. Mechanisms and management. Eds.: Wasterline C., Teiman D.M. The MIT Press, (2006).

26. Turski, W. A.: Pilocarpine-induced seizures in rodents -17 years on, Polish Journal of Pharmacology, 52, 63-65 (2000).

27. Cavalheiro, E.A.: The pilocarpine model of epilepsy Italian Journal of Neurological Sciences, 16, 33-37 (1995).

28. Chaudhary, G. and Gupta, Y. K.: Lithium does not synergize the peripheral action of cholinomimetics as seen in the cen- tral nervous system. Life Sciense, 68, 2115-2121 (2001).

29. Cavalheiro, E. A., Leite, J. P., Bortolotto, Z. A., Turski, W. A., Ikonomidou, C. and Turski, L.: Long-term effects of pilocarpine in rats: structural damage of the brain triggers kindling and spontaneous recurrent seizures. Epilepsia 32, 778782 (1995).

30. Avanzini, G. and Farello R.: Animal model of epilepsies. In: Molecular and cellular targets for anti-epileptic drugs. Eds.: G. Avanzini, Regesta G. et al., John Libbey. London (2000).

31. Berkely, J. L., Decker, M. J. and Levey, A. I.: The role of muscarinic acetylcholine receptor-mediated activation of extracellular signal-regulated kinase $1 / 2$ in pilocarpine-induced seizures//Journ. of Neurochenistry, 82, 192-201 (2002).

32. Jones, D. M., Esmaeil, N., Maren, S. and MacDonald, R. L.: Characterization of pharmacoresistance to benzodiazepines in the rat Li-pilocarpine model of status epilepticus. Epilepsy Res., 50, 301-312 (2002).

33. Honchar, M. P., Olney, J. W. and Sherman, W. R.: Systemic cholinergic agents induce seizures and brain damage in lithium-treated rats. Science, 220(4594), 323-325 (1983).

34. Van Camp, N., D'Hoog, R., Derhoye, M. and Peeters, R. R.: Smultaneous EEG recordingggg and functional magnetic resonance imaging during pentylenetetrazol-induced seizures in rat. Neurimage, 19, 627-636 (2003).

35. Konstantinova, N. F., Makhankov, V. V., Uvareova, N. I., Samoshina, N. F., Sova, V. V. and Michailova O. M.: Study on the dynamic of biosynthesis of ginsenozides the growth cycle cell culture of ginseng. Biotekhnolobgia, 9-10, 35-39 (1995).

36. Kondratyev, A. and Gale, K.: Latency to onset of status epilepticus determines molecular mechanisms of seizure-induced cell death. Molecular Brain Research, 121, 86-94 (2004).

37. Niimura, M., Moussa, R., Bisson. N. and Ikeda-Duglas, C. et al.: Changes phosphorilation of the NMDA receptor in the rat hippocampus induced by status epilepticus. Journ. Neurochemistry 92, 1377-1385(2005).

38. Chepurnova, N. E., De Curtis, Uva, L., Chepurov, S. A., Redkozubova, O. M. and Gonchaov, O. B.: Status epilepticus in rat and Guinea pig (lithium-pilocarpine and PTZ models)/ /Epilepsia, 46, Spl. 6, 364 (2005).

39. Shuler, P., Hentshel, D., Stefan, H. and Huk, W.: Quantitive magnetic resonance imaging (qMRI) and spectroscopy (qMRS) in epilepsies. : In: "Focus localization". Eds.: G. Pawlik, H.Stefan. Koln,Germany, 79-94 (2000).

40. Roch, C., Leroy, Cl., Nehlig, A. and Namer, I.: magnetic resonnce imaging in te study of the lithium-pilocarpine model of temporal lobe epilepsy in adult rats. Epi;lepsia 43(4), 325335, (2002).

41. Spinella, M.: Herbal medicines and epilepsy. The potential for benefit and adverse effects. Epilepsy \& Behavior, 2, 524532 (2001).

42. Finn, Z. and Lennart, D.: Phytotherapy. Experimental and 
clinichen ginseng trials. www. nycomed.ru.

43. Tanaka, O. and Kasai, R.: Saponins of ginseng and related plants. Progress in the Chemistry of Organic Natural Products, 46, 1-42 (1984),

44. Vogler, B. K., Pittler, M. H. and Ernst, E.: The efficacy of ginseng: a systematic review of randomised clinical trials. Eur J Clin Pharmacol., 55, 567-575 (1999).

45. Lian, X. Y., Zhang, Z. Z. and Stringer, J. L.: Anticonvulsant activity of ginseng on seizures induced by chemical convulsants. Epilepsia; 46(1), 15-22 (2005),

46. Park, J.-K., Jin, S.-H., Choi, K.-H., Ko, J.-H. and Nam, K.-Y.: Influence of ginsenosides on the kainik acid -indiced seizure activity in immaturerats : Journ. Biochem. Molec. Biol., 32, 339-344 (1999).

47. Park, J.-K., Jin, S.-H., Choi, K.-H., Ko, J0-H. et al.: Effect of herbal preparation containing ginsend on learning and memory in kainite-indiced seizures In : Proceed of Intern Symp for the development of medical plants. Korea, Inje Kun, 2000 The Plant resource Society of Korea \&th Inern Symposium 84-95 (2000).

48. Lee, J.-H., Kim, S.-R., Bae, C.-S., Kim, D., Hong, H.-N. and Nah, S-Y.: Protective effect of ginsenosides, active ingredients of Panax ginseng, on kainic acid-induced neurotoxicity in rat hippocampus. Neuroscience Letters, 325, 129-133. (2002).

49. Lee, J. K., Choi, S. S., Lee, H. K. et al.: Effects of ginsenosides $\mathrm{Rd}$ and decursinol on the neurotoxic responces induced by kainic acid in mice. Planta Med., 69, 230-234 (2003).

50. Majores, M., Eils, J., Wiestler, O. D. and Becker, A. J.: Molecular profiling of temporal lobe epilepsy: comparison of data from human tissue samples andanimal models. Epilepsy Research (2004).

51. Kim, H. S., Kim, K. S. and Oh, K. W.: Inhibition by ginsenosides $\mathrm{Rb}_{1}$ and $\mathrm{Rg}_{1}$ of cocaine- induced hyperactivity conditionedplace preference, and postsynaptic dopamine receptor supersensitivity in mice. Pharmacol. Biochem. Behav., 63, 407-412 (1999).

52. Tachikawa, E., Kudo, K., Harada, K., Kashimoto, T., Miyate, Y., Kakizaki, A. and Takahashi, E.: Effects of ginseng saponins on responses induced by various receptor stimuli. European Journ. Pharmacol., 369, 23-32 (1999).

53. Choi, S. E., Choi, S., Lee, J. H., Whiting, P. J., Lee, S. M. and Nah, S. Y.: Effects of ginsenosides on $\operatorname{GABA}(\mathrm{A})$ receptor channels expressed in Xenopus oocytes. Archives of Pharmacol. Res., 26, 28-33 (2003).

54. Kim, H. S., Lee, J. H., Goo, Y. S. and Nah, S. Y.: Effects of ginsenosides on $\mathrm{Ca}+2$ Channels and membrane capacitance in rat adrenal chromaffin cells. Brain Research Bulletin, 46, 245-251 (1998).

55. Mook-Jung, I., Hong, H. S., Boo, J. H., Lee, K. H., Yun, S. H., Cheong, M. Y., Joo, I., Huh, K. and Jung, M. W.: Ginse- noside $\mathrm{Rb}_{1}$ and $\mathrm{Rg}_{1}$ improve spatial learning and increase hippocampal synaptophysin level in mice. Journ. Neurosci. Res., 63, 509-615 (2001).

56. Lim, J. H., Wen, T. C., Matsuda, S., Tanaka, J., Maeda, N., Peng, H., Aburaya, J., Ishihara, K., and Sakanaka, M.: Protection of ischemic hippocampal neurons by ginsenoside $\mathrm{Rb}_{1}$, a main ingredient of ginseng root. Neuroscience Research, 28, 191-200 (1997).

57. Wen, T. C., Yoshimura, H., Matsuda, S., Lim, J. H. and Sakanaka, M.: Ginseng root prevents learning disability and neuronal loss in gerbils with 5-minute forebrain ischemia. Acta Neuropathology, 91, 15-22 (1996).

58. Benishin, C. G., Lee, R., Wang, L. C. and Liu, H. J.: Effects of ginsenoside $\mathrm{Rb}_{1}$ on central cholinergic metabolism. Pharmacology, 42, 223-229 (1991).

59. Smolders, I., Khan, G. M., Manil, J., Ebinger, G. and Michotte, Y.: NMDA receptor-mediated pilocarpine-induced seizures: Characterization in freely moving rats by microdialysis, British Journ. Pharmacol., 121(6), 1171-1179 (1997).

60. Kim, S., Ahn, K., Oh, T. H., Nah, S. Y. and Rhim, H.: Inhibitory effect of ginsenosides on NMDA receptor-mediated signals in rat hippocampal neurons. Biochem. Biophysic. Research Commun., 296, 247-254 (2002).

61. Kim, S. and Rhim, H.: Ginsenosides inhibit NMDA receptormediated epileptic discharges in cultured hippocampal neurons. Arch. Pharm. Res., 27(5), 524-530 (2004).

62. Shen, L. and Zhang, J.: Ginsenoside $\mathrm{Rg}_{1}$ increases ischemiainduced cell proliferation and survival in the dentate gyrus of adult gerbils. Neuroscience Letters, 344, 1-4 (2003).

63. Liao, B., Newmark, H. and Zhou, R.: Neuroprotective effects of ginseng total saponin and ginsenosides $\mathrm{Rb}_{1}$ and $\mathrm{Rg}_{1}$ on spinal cord neurons in vitro. Experimental Neurology., 173, 224-234 (2002).

64. Salim, K. N., McEwen, B. S. and Chao, H. M.: Ginsenoside $\mathrm{Rb}_{1}$ regulates ChAT, NGF and trkA mRNA expression in the rat brain. Molecular Brain Research, 47, 177-182 (1997).

65. Lee, S. H., Yand, S. C., Park, J. K., Jung, M. W. and Lee, C.J.: Reduction ofelectrical evoked neural; activity by ginseng saponin in rat hippocampal slices. Biol. And Pharmacol. Bulletin 173, 224-234 (2000).

66. Lee, Jum-Ho, Jeong, Sang Mi, Kim, Jong-Hoon, Lee, ByungHwan et al.: Characteristics of ginsenoside $\mathrm{Rg}_{3}$-mediated brain Na+ current inhibition. Molec. Parmocology. 68, 11141126 (2005).

67. Li, J. and Zhang, J.: Inhibition of apoptosis by ginsenoside $\mathrm{Rg}_{1}$ in cultured cortical neurons. Chin. Med J, 110(7), 535539 (1997).

68. Young, C. Kim, So, R. Kim, George J. Ma, rkelonis, and Tae, H. Oh.: Ginsenosides $\mathrm{Rb}_{1}$ and $\mathrm{Rg}_{3}$ protect cultured rat cortical cells from glutamate-induced neurodegeneration, Journal of Neuroscience Research, 53, 426-432 (1998). 
69. Hiai, S., Yokoyama, H., Oura, H. and Yano, S.: Stimulation of pituitary- adrenocortical system by ginseng saponin. Endocrinol. Jpn., 26, 661-665 (1979).

70. Lee, Y. J., Chung, E., Lee, K. Y., Lee, Y. H., Huh, B. and Lee,
S. K.: Ginsenoside- $\operatorname{Rg}_{1}$, one of the major active molecules from Panax ginseng, is a functional ligand of glucocorticoid receptor. Mol. Cell. Endocrinol., 133, 135-140 (1997). 